\title{
A Study on the Income Inequalities among NREGS Beneficiaries in Mandi District of Himachal Pradesh
}

\section{Tek Singh}

Government P. G. College, Mandi, Himachal Pradesh, India

Corresponding author: teksingh1177@gmail.com

\begin{abstract}
Inequality is more visible and widespread in the developing countries of the world like India. The National Rural Employment Guarantee Scheme (NREGS) is a flagship programme of poverty alleviation and reducing income inequalities, of the Government of India. The programme seeks to guarantee at least 100 days of employment every year to the rural poor or enhance livelihood security by 100 days of employment a year to one member of every rural unemployed family. In this paper, an attempt is made to study the magnitude of inequalities in the distribution of household income among the MNREGA beneficiaries in the economy Mandi district of Himachal Pradesh. This study shows that there still exists income inequality in all categories of land holdings and the reduction of income inequality may be caused due to reason that the members of all categories of land holdings obtained more employment opportunities under NREGS or MNREGA.

Highlights

The highlights of the research paper are enlisted as follows:

( The research paper is focused upon exploration of income inequalities among NREGS beneficiaries in Mandi district of Himachal Pradesh.

(0) The study reveals that there still exists income inequality in all categories of land holdings \& the reduction of income inequality may be caused due to reason that the members of all categories of land holdings obtained more employment opportunities under NREGS or MNREGA.
\end{abstract}

Keywords: NREGS, Medium, inequalities, beneficiaries, poverty

Inequality is more visible and widespread in the developing countries of the world like India. Government of India has undertaken a number of programmes to reduce the inequality in rural areas. NREGA is one of such efforts in the country. The National Rural Employment Guarantee Scheme (NREGS) is a flagship poverty alleviation programme of the Government of India, which seeks to guarantee at least 100 days of employment every year to the rural poor or enhance livelihood security by 100 days of employment a year to one member of every rural unemployed family (Sontakki and Ahire, 2011). Poverty as a concept is closely related to inequality. Given the average income level, a higher level of inequality (reflected by the usual measures) will tend to be associated with a higher level of poverty. Furthermore, the so- called 'poverty line' may sometimes we drawn in the light of the socially accepted "minimum" standard of living and the later can be influenced by the average income level so that poverty measures, thus defined, may catch an aspect of relative inequality as well (Sen, 1974).

There are two broad concepts of poverty: relative poverty and absolute poverty. The relative poverty is measured in the terms of inequality in the distribution of income; whereas, absolute poverty is reckoned in terms of some kind of notion of subsistence considered appropriate to the circumstances of the country (or group of countries) concerned (Department of Economics and Social Affairs, 1975). The Mahatama Gandhi National 
Rural Employment Guarantee Act was notified by the Government of India on September, 2005 and was made effective w.e.f. $2^{\text {nd }}$ February, 2006. In the $1^{\text {st }}$ Phase, the Mahatama Gandhi National Rural Employment Guarantee Scheme (MNREGA) was introduced in District Chamba and Sirmaur on $2^{\text {nd }}$ February, 2006. In second phase MNREGA was started in District Kangra and Mandi w.e.f. 1-4-2007. In the third phase w.e.f. 1-4-2008, it covered all the remaining 8 district of the State. During the year 2014-15 Central share amount to ₹ 28,569.29 lakh and State share amounting to ₹ 3,163.57 lakh have been credited in the State Employment Guarantee Fund Account. The total availability of funds with the Districts is ₹ $33,770.58$ lakh is available in the State Employment Guarantee Fund account against which the funds amounting to ₹ 31,533.94 lakh have been utilized and 132.68 lakh mandays have been generated by providing employment to $3,82,250$ households (Government of Himachal Pradesh, 2015).

The utilization of funds under MNREGS in Himachal Pradesh has been found encouraging one. Because maximum utilization of funds have been done in all the years. The percentage of utilization of funds remained above 80.00 per cent, with an exception of the year 2010-11, in which the utilization of funds was found lowest, that is, 66.53 per cent (Government of Himachal Pradesh, 2010-11 to 2015-16). Keeping this in view, this study proposed to measure inequalities among MNREGA'S beneficiaries in Mandi district of Himachal Pradesh where, inequality is still abysmal in many regions. Unemployment is still increasing because educated and skilled individuals are not getting work. The situation is particularly worse in villages, because a large segment of society owns minimum resources of land, water etc.

\section{Literature Review}

A general review of literature of the period shows that the researchers were very much interested in eradicating the inequality over the years. Rajanna and Ramesh (2009) revealed that NREGP has become a beacon of light in the rural areas, and contributed substantially for the increased living and economic conditions by reducing the income imbalance in the rural area. Roy (2009) concluded that creation of durable community assets like rural road, water bodies, tanks, market sheds for the unemployed youths have brought a shift in the livelihood of rural people. Banerjee and Saha (2010) concluded that due to implementation of NREGA, there was increase in wage rates which resulted in increase in household income of the rural poor. In the study regions of Chhattisgarh, the net household income increased in the range of 60 per cent to 70 percent, while in Jharkhand and Orissa it was 60-70 per cent and 30-40 per cent respectively. Hirway (2010) findings revealed that at the all- India level, the NREGA income per household has increased from ₹ 1920.0 in 2006-07 to ₹ 4400.7 in 2009-10 indicating an almost 130 per cent increase. In sum, it has been concluded that the extent of inequalities has come down after implementation of MGNREGA.

\section{Objectives}

The main objective of the present study is:

1. To examine as to what extent this programme has succeeded in the reduction of income inequalities among the sampled households in the Mandi district of Himachal Pradesh.

\section{Data Source and Methodology}

In the present study, Mandi district has been selected purposively for conducting the present empirical verification on the impact of NREGA, mainly due to the reason that NREGA was started in Mandi district in Phase-II i.e. $1^{\text {st }}$ April 2007 as well as this district represent diverse agro-climatic conditions and the physical and financial performance of NREGA are moderate and close to the State average. The study is mainly based on primary data. The required primary data have been collected with the help of a pre-tested schedule from 300 sample households of 18 villages during 2007-08 and 2010-11selected randomly from the two development blocks of the district. With the help of pre-tested schedules, informations, pertaining to age and sex-wise family composition, educational status, consumer units as well as the data regarding income and consumption have been recorded from all the sample households in the schedule used in the survey. The impact of NREGA on income disparities or inequalities have been analysed through the (a) Gini-coefficient (b) Co-efficient of Variation and (c) Standard deviation of logarithms. All these three methods have been used because each of them is more sensitive than 
A Study on the Income Inequalities among NREGS Beneficiaries in Mandi... CP

others to depict correct changes in different parts of the size distribution of income. For example, the Gini-coefficient is relatively more sensitive to changes in the middle ranges than to the changes in extreme ranges of size distribution of income because it depends upon the rank order weights of income recipients and on the number of recipients in a given range. The coefficient of variation, on the other hand is more sensitive to changes in upper ranges of income distribution, since it attaches equal weights to transfer at all levels of income. The standard deviation of logarithms, derived by expressing the incomes in logarithms, is a measure which is more sensitive to changes is the lower ranges than in the other parts of the distribution (Balisacan, 1993).

Gini -coefficient may be computed mathematically as follows (Sen, 1974).

The value of Gini-coefficient for the income distribution of all sample households has been worked out with the help of following formula:

$$
G(Y)=1+(1 / n)-\left(2 / n^{2} z\right) \sum_{i=1}^{n}(n+1-i) y i
$$

Where:

$G(Y)=$ Gini- coefficient of the income distribution of sample households.

$n=$ population size

$z=$ mean income

$y i=$ income of the $i^{\text {th }}$ person

The value of Gini-coefficient of the income inequalities among the poor have been worked out with the help of following formula:

$$
G(Y)=1+(1 / q)-\left(2 / q^{2} z\right) \sum_{i=1}^{n}(q+1-i) y i
$$

Where:

$G(Y)=$ Gini- coefficient of the income distribution of the poor

$q=$ number of people below poverty line

$z=$ mean income of the poor

$y i=$ income of the $i^{\text {th }}$ poor person

Standard deviation is the most important and widely used measures of studying absolute dispersion. It is defined as the square root of the mean of the squared deviations from the arithmetic mean. It measures the absolute dispersion or variability of distribution; the greater the amount of dispersion the greater the standard deviation. It has been calculated with the help of following formula (Croxton, Frederic, 1979).

$$
\text { Standard deviation }(\mathrm{SD})=\sqrt{\left[\sum \times 2 / n\right]}
$$

Where $x=X-X$, i.e. deviations of the items from means; and $N=$ is the number of observation.

Or

$$
\text { Standard deviation }(\mathrm{SD})=\sqrt{[\Sigma d 2 / N]-[\Sigma d / N] 2}
$$

Where $d=X-A$, i.e. deviations of the items from assumed means; and $N=$ is the number of observation.

Co-efficient of variation is the relative measure of dispersion and will be obtain as follows:

Co-efficient of variation $(\mathrm{CV})=$

$$
\frac{\text { Standard Deviation }}{\text { Mean }} \times 100
$$

\section{RESULTS AND DISCUSSION}

\section{Magnitude of Inequalities in the Distribution of household income}

The Magnitude of Inequalities has been worked out with the help of Gini co efficient ratio, co-efficient of variation as well as by applying the Standard deviation of logarithms.

\section{Distribution of Monthly Household Income among the Marginal Holdings Before and After the Implementation of MGNREGA}

The cumulated percentages of the household monthly income of marginal holdings and the number of person failing in each income group has been calculated with the help of Gini- coefficient for the income distribution of marginal holdings before the implementation of MGNREGA has been worked out as follow:

$$
G(Y)-1+(1 / n)-\left(2 / n^{2} z\right) \sum_{i=1}^{n}(n+1-i) y i
$$


P S Singh

Where:

$G(y)=$ Gini- coefficient of the income distribution of the households.

$n=$ population size

$z=$ mean income $(₹)$

$y i=$ income of the $i^{\text {th }}$ person

$$
\begin{aligned}
& \sum_{i=1}^{n}(n+1-i) y i=31513740.45 \\
& z=125816.80 / 721.5=174.38 \\
& n=721.5
\end{aligned}
$$

Thus,

$$
\begin{aligned}
\mathrm{G}(\mathrm{y}) & =1+(1 / 721.5)-\left(2 / 721.5^{2} \times 174.38\right)(31513740.45) \\
& =1+0.001386-(2 / 90775645.16)(31513740.45) \\
& =1.001386-0.694321 \\
& =0.3070
\end{aligned}
$$

The cumulated percentages of the household monthly income of marginal holdings after the implementation of MGNREGA has been worked out with the help of the formula mentioned above as follow:

$$
\begin{aligned}
& \sum_{i=1}^{n}(n+1-i) y i=36575579.13 \\
& z=139893.20 / 721.5=193.89 \\
& n=721.5
\end{aligned}
$$

Thus,

$$
\begin{aligned}
\mathrm{G}(\mathrm{y}) & =1+(1 / 721.5)-\left(2 / 721.5^{2} \times 193.89\right)(36575579.13) \\
& =1+0.001386-(2 / 100931814.65)(36575579.13) \\
& =1.001386-0.724758 \\
& =0.2766
\end{aligned}
$$

\section{Distribution of Monthly Household Income among the Small Holdings Before and After the Implementation of MGNREGA}

The cumulated percentages of the household monthly income of small holdings before the implementation of MGNREGA has been worked out with the help of the formula mentioned above as follow:

$$
\sum_{i=1}^{n}(n+1-i) y i=12556141.55
$$

$$
\begin{aligned}
& z=109125.10 / 340.4=320.58 \\
& n=340.4
\end{aligned}
$$

Thus,

$$
\begin{aligned}
\mathrm{G}(\mathrm{y})= & 1+(1 / 340.4)-\left(2 / 340.4^{2} \mathrm{X} 320.58\right)(12556141.55) \\
= & 1+0.0029377-(2 / 37146297.05)(12556141.55) \\
= & 1.0029377-0.6760373 \\
& 0.3269
\end{aligned}
$$

The cumulated percentages of the household monthly income of small holdings after the implementation of MGNREGA has been worked out with the help of the formula mentioned above as follow:

$$
\begin{aligned}
& \sum_{i=1}^{n}(n+1-i) y i=15740200.04 \\
& \mathrm{z}=127983.24 / 340.4=375.97 \\
& \mathrm{n}=340.4
\end{aligned}
$$

Thus,

$$
\begin{aligned}
\mathrm{G}(\mathrm{y}) & =1+(1 / 340.4)-\left(2 / 340.4^{2} \times 375.97\right)(15740200.04) \\
& =1+0.0029377-(2 / 43564455.99)(15740200.04) \\
& =1.0029377-0.7226166 \\
& =0.2803
\end{aligned}
$$

Distribution of Monthly Household Income among the Medium Holdings Before and After the Implementation of MGNREGA

The cumulated percentages of the household monthly income of medium holdings before the implementation of MGNREGA has been worked out with the help of the formula mentioned above as follow:

$$
\begin{aligned}
& \sum_{i=1}^{n}(n+1-i) y i=5868220.86 \\
& z=91756.23 / 195.7=468.86 \\
& n=195.7
\end{aligned}
$$

Thus,

$$
\begin{aligned}
\mathrm{G}(\mathrm{y}) & =1+(1 / 195.7)-\left(2 / 195.7^{2} \times 468.86\right)(5868220.86) \\
& =1+0.0051098-(2 / 17956630.02)(5868220.86) \\
& =1.0051098-0.6535993 \\
& =0.3515
\end{aligned}
$$

The cumulated percentages of the household monthly income of medium holdings after the 
A Study on the Income Inequalities among NREGS Beneficiaries in Mandi... CP

implementation of MGNREGA has been worked out with the help of the formula mentioned above as follow:

$$
\begin{aligned}
& \sum_{i=1}^{n}(n+1-i) y i=8002223.68 \\
& z=113954.50 / 195.7=582.29 \\
& n=195.7
\end{aligned}
$$

Thus,

$$
\begin{aligned}
\mathrm{G}(\mathrm{y}) & =1+(1 / 195.7)-\left(2 / 195.7^{2} \times 582.29\right)(8002223.68) \\
& =1+0.0051098-(2 / 22300827.74)(8002223.68) \\
& =1.0051098-0.7176616 \\
& =0.2875
\end{aligned}
$$

Distribution of Monthly Household Income among the All Holdings Before and After the Implementation of MGNREGA

The cumulated percentages of the household monthly income of all holdings before the implementation of MGNREGA has been worked out with the help of the formula mentioned above as follow:

$$
\begin{aligned}
& \sum_{i=1}^{n}(n+1-i) y i=138744259.40 \\
& z=326698.10 / 1257.6=259.77 \\
& n=1257.6
\end{aligned}
$$

Thus,

$$
\begin{aligned}
\mathrm{G}(\mathrm{y}) & =1+(1 / 1257.6)-\left(2 / 1257.6^{2} \times 259.77\right)(138744259.40) \\
& =1+0.0007951-(2 / 410841259.31)(138744259.40) \\
& =1.0007951-0.6754154 \\
& =0.3253
\end{aligned}
$$

The cumulated percentages of the household monthly income of all holdings after the implementation of MGNREGA has been worked out with the help of the formula mentioned above as follow:

$$
\begin{aligned}
& \sum_{i=1}^{n}(n+1-i) y i=153943067.10 \\
& z=342064.05 / 1257.6=271.99 \\
& n=1257.6
\end{aligned}
$$

Thus,

$$
\begin{aligned}
& \mathrm{G}(\mathrm{y})=1+(1 / 1257.6)-\left(2 / 1257.6^{2} \times 271.99\right)(153943067.10) \\
& =1+0.0007951-(2 / 430167895.14)(153943067.10) \\
& =1.0007951-0.7157348 \\
& =0.2850
\end{aligned}
$$

The value of Gini-coefficient for the income distribution of households falling on the all holding groups (i.e. marginal, small and medium) before the implementation of MGNREGA if compared to the value of Gini-coefficient for the income distribution of households falling on the all holding groups (i.e. marginal, small and medium) after the implementation of MGNREGA clearly indicate that the inequality of income is higher in the former cases as compared to the latter.

\section{Distribution of Monthly Household Income among the Poor Holdings Before and After the Implementation of MGNREGA}

The cumulated percentages of the household monthly income of poor holdings and the number of person failing in each income group has been calculated with the help of Gini- coefficient for the income distribution of poor holdings before the implementation of MGNREGA has been worked out as follow:

$$
G(y)=(1+1 / q)-\left(2 / q^{2} z\right) \sum_{i=1}^{n}(n+1-i) y i
$$

Where:

$G(y)=$ Gini-coefficient of the income distribution of the poor.

$q=$ number of people below poverty line.

$z=$ mean income of the poor (₹)

$y i=$ income of the $i^{\text {th }}$ poor person

$$
\begin{aligned}
& \sum_{i=1}^{n}(q+1-i) y i=16080519.66 \\
& z=69558.18 / 609.8=114.06 \\
& q=609.8
\end{aligned}
$$

Thus,

$$
\begin{aligned}
\mathrm{G}(\mathrm{y}) & =1+(1 / 609.8)-\left(2 / 609.8^{2} \times 114.06\right)(16080519.66) \\
& =1+0.001639-(2 / 42413899.92)(16080519.66) \\
& =1.001639-0.758266 \\
& =0.2433
\end{aligned}
$$

The cumulated percentages of the household monthly income of poor holdings after the implementation of MGNREGA has been worked out with the help of the formula mentioned above as follow: 


$$
\begin{aligned}
& \sum_{i=1}^{n}(q+1-i) y i=15335891.71 \\
& z=68987.24 / 569.9=121.05 \\
& q=569.9
\end{aligned}
$$

Thus,

$$
\begin{aligned}
\mathrm{G}(\mathrm{y}) & =1+(1 / 569.9)-\left(2 / 569.9^{2} \times 121.05\right)(15335891.71) \\
& =1+0.001754-(2 / 39315346.51)(15335891.71) \\
& =1.001754-0.780147 \\
& =0.2216
\end{aligned}
$$

It may be concluded that the value of the income distribution of all households if compared to the value of Gini-coefficient of the income distribution among the poor clearly indicate that the inequality of income is higher in the former case as compared to the latter because in the latter case comparatively the value of Gini-coefficient is higher which shows relatively more skewed income distribution. The income of the poor is low due to their small size of holdings, large families accompanied by more dependents and lack of regular source of income.

\section{Dispersion of Monthly Household Income among the Marginal Holdings Before and After the Implementation of MGNREGA}

The dispersion of the household monthly income of marginal holdings and the number of person failing in each income group has been calculated with the help of Standard deviation and Co-efficient of variation for the income distribution of marginal holdings before the implementation of MGNREGA has been worked out as follow:

$$
\text { Standard deviation }(\mathrm{SD})=\sqrt{[\Sigma d 2 / N]-[\Sigma d / N] 2}
$$

Where $d=X-A$, i.e. deviations of the items from assumed means; and $N=$ is the number of observation.

$$
\begin{aligned}
& \sum \mathrm{d}^{2}=608885413.70 \\
& \sum \mathrm{d}=-324213.00 \\
& \mathrm{~N}=180 \\
& =\sqrt{[608885413.70 / 180]-[-324213.00 / 180] 2} \\
& =\sqrt{([3382696.74]-[-1801.18] 2} \\
& =\sqrt{[3382696.74]-[3244249.39]}
\end{aligned}
$$

$=\sqrt{138447.35}$

$=372.08$

Co-efficient of variation $(\mathrm{CV})=$

$$
\frac{\text { Standard Deviation }}{\text { Mean }} \times 100
$$

S.D. $=372.08$

Assumed Mean $=1985.00$

Thus, $(\mathrm{CV})=372.08 / 1985.00 \times 100$

$$
=18.74
$$

The dispersion of the household monthly income of marginal holdings after the implementation of MGNREGA has been worked out with the help of the formula mentioned above as follow:

$$
\begin{aligned}
& \sum \mathrm{d}^{2}=670781414.10 \\
& \sum \mathrm{d}=-341146.18 \\
& \mathrm{~N}=180 \\
& =\sqrt{[670781414.10 / 180]-[-341146.18 / 180] 2} \\
& =\sqrt{[3726563.41]-[-1895.26] 2} \\
& =\sqrt{[3726563.41]-[3592010.47]} \\
& =\sqrt{134552.94}
\end{aligned}
$$

S.D. $=366.81$

Assumed Mean $=2093.00$

Thus, $(C V)=366.81 / 2093.00 \times 100$

$$
=17.52
$$

\section{Dispersion of Monthly Household Income among the Small Holdings Before and After the Implementation of MGNREGA}

The dispersion of the household monthly income of small holdings before the implementation of MGNREGA has been worked out with the help of the formula mentioned above as follow:

$$
\begin{aligned}
& \sum \mathrm{d}^{2}=93256427.70 \\
& \sum \mathrm{d}=-79520.80 \\
& \mathrm{~N}=80 \\
& =\sqrt{[93256427.70 / 80]-(-79520.80 / 80) 2} \\
& =\sqrt{[1165705.34]-(-994.01) 2} \\
& =\sqrt{[1165705.34]-[988055.88]} \\
& =\sqrt{177649.46} \\
& =421.48
\end{aligned}
$$


A Study on the Income Inequalities among NREGS Beneficiaries in Mandi... $\mathcal{C P}$

S.D. $=421.48$

Assumed Mean $=1330.00$

Thus, $(\mathrm{CV})=421.48 / 1330.00 \times 100$

$$
=31.69
$$

The dispersion of the household monthly income of small holdings after the implementation of MGNREGA has been worked out with the help of the formula mentioned above as follow:

$$
\begin{aligned}
& \sum \mathrm{d}^{2}=116678774.60 \\
& \sum \mathrm{d}=-90547.79 \\
& \mathrm{~N}=80 \\
& =\sqrt{[116678774.60 / 80]-[-90547.79 / 80] 2} \\
& =\sqrt{[1458484.68]-(-1131.84) 2} \\
& =\sqrt{[1458484.68]-[1281061.79]} \\
& =\sqrt{177422.89} \\
& =421.20
\end{aligned}
$$

S. D. $=421.20$

Assumed Mean $=1497.00$

Thus, $(\mathrm{CV})=421.20 / 1497.00 \times 100$

$$
=28.13
$$

Dispersion of Monthly Household Income among the Medium Holdings Before and After the Implementation of MGNREGA

The dispersion of the household monthly income of medium holdings before the implementation of MGNREGA has been worked out with the help of the formula mentioned above as follow:

$$
\begin{aligned}
& \sum \mathrm{d}^{2}=223873572.60 \\
& \sum \mathrm{d}=-86554.10 \\
& \mathrm{~N}=40 \\
& =\sqrt{[223873572.60 / 40]-[-86554.10 / 40] 2} \\
& =\sqrt{[5596839.31]-(-2163.85) 2} \\
& =\sqrt{[5596839.31]-[4682246.82]} \\
& =\sqrt{914592.49} \\
& =956.34 .
\end{aligned}
$$

S. D. $=956.34$

Assumed Mean $=2735.00$
Thus, $(C V)=956.34 / 2735.00 \times 100$

$$
=34.96
$$

The dispersion of the household monthly income of medium holdings after the implementation of MGNREGA has been worked out with the help of the formula mentioned above as follow:

$$
\begin{aligned}
& \sum \mathrm{d}^{2}=321933457.60 \\
& \sum \mathrm{d}=-107053.31 \\
& \mathrm{~N}=40 \\
& =\sqrt{[321933457.60 / 40]-[-107053.31] 2} \\
& =\sqrt{[8048336.44]-(-2676.33) 2} \\
& =\sqrt{[8048336.44]-[7162742.26]} \\
& =\sqrt{885594.18} \\
& =941.06
\end{aligned}
$$

S. D. $=941.06$

Assumed Mean $=3286.00$

Thus, $(C V)=941.06 / 3286.00 \times 100$

$$
=28.63
$$

\section{Dispersion of Monthly Household Income} among the All Holdings Before and After the Implementation of MGNREGA

The dispersion of the household monthly income of all holdings before the implementation of MGNREGA has been worked out with the help of the formula mentioned above as follow:

$$
\begin{aligned}
& \sum \mathrm{d}^{2}=1866034527.00 \\
& \sum \mathrm{d}=-720487.53 \\
& \mathrm{~N}=300 \\
& =\sqrt{[1866034527.00 / 300]-[-720487.53 / 300] 2} \\
& =\sqrt{[6220115.09]-(-2401.62) 2} \\
& =\sqrt{[6220115.09]-[57677778.62]} \\
& =\sqrt{452336.47} \\
& =672.56
\end{aligned}
$$

S. D. $=672.56$

Assumed Mean $=2718.00$

Thus $(C V)=672.56 / 2718.00 \times 100$

$$
=24.74
$$


Y) Singh

The dispersion of the household monthly income of all holdings after the implementation of MGNREGA has been worked out with the help of the formula mentioned above as follow:

$$
\begin{aligned}
& \sum \mathrm{d}^{2}=2707401134.00 \\
& \sum \mathrm{d}=-880107.28 \\
& \mathrm{~N}=300 \\
& =\sqrt{[2707401134.00 / 300]-[-880107.28 / 300] 2} \\
& =\sqrt{[9024670.44]-(-2933.69) 2} \\
& =\sqrt{[9024670.44]-[8606537.01]} \\
& =\sqrt{418133.43} \\
& =646.63
\end{aligned}
$$

S. D. $=646.63$

Assumed Mean $=3265.00$

$$
\text { Thus, } \begin{aligned}
(\mathrm{CV}) & =646.63 / 3265.00 \times 100 \\
& =19.80
\end{aligned}
$$

The value of Standard deviation and Co-efficient of variation for the income distribution of households falling on the all holding groups (i.e. marginal, small and medium) before the implementation of MGNREGA if compared to the value of Standard deviation and Co-efficient of variation for the income distribution of households falling on the all holding groups (i.e. marginal, small and medium) after the implementation of MGNREGA clearly indicate that the dispersion or variability of income is higher in the former cases as compared to the latter.

\section{Dispersion of Monthly Household Income among the Poor Holdings Before and After the Implementation of MGNREGA}

The dispersion of the household monthly income of poor holdings before the implementation of MGNREGA has been worked out with the help of the formula mentioned above as follow:

$$
\begin{aligned}
& \sum \mathrm{d}^{2}=207956.32 \\
& \sum \mathrm{d}=-1585.88 \\
& \mathrm{~N}=135 \\
& =\sqrt{[207956.32 / 135]-[-1585.88 / 135] 2} \\
& =\sqrt{[1540.41]-(-11.74) 2}
\end{aligned}
$$

$$
\begin{aligned}
& =\sqrt{[1540.41]-[137.82]} \\
& =\sqrt{1402.59} \\
& =37.45
\end{aligned}
$$

S. D. $=37.45$

$$
\begin{aligned}
& \text { Assumed Mean }=81.00 \\
& \text { Thus, } \begin{aligned}
(\mathrm{CV}) & =37.45 / 81.00 \times 100 \\
& =46.23
\end{aligned}
\end{aligned}
$$

The dispersion of the household monthly income of poor holdings after the implementation of MGNREGA has been worked out with the help of the formula mentioned above as follow:

$$
\begin{aligned}
& \sum \mathrm{d}^{2}=172691.11 \\
& \sum \mathrm{d}=-1123.61 \\
& \mathrm{~N}=125 \\
& =\sqrt{[172691.11 / 125]-(-1123.61 / 125) 2} \\
& =\sqrt{[1381.52]-(-8.99) 2} \\
& =\sqrt{[1381.52]-[80.82]} \\
& =\sqrt{1300.70} \\
& =36.06
\end{aligned}
$$

S. D. $=36.06$

Assumed Mean $=84.00$

Thus, $(\mathrm{CV})=36.06 / 84.00 \times 100$

$$
=42.92
$$

The value of Standard deviation and Co-efficient of variation for the income distribution of households falling on the poor holding groups before the implementation of MGNREGA if compared to the value of Standard deviation and Co-efficient of variation for the income distribution of households falling on the poor holding groups after the implementation of MGNREGA clearly indicate that the dispersion or variability of income is higher in the former case as compared to the latter.

\section{CONCLUDING REMARKS}

The standard deviation, coefficient of variation and Gini-coefficient decreased in all the categories of land holdings after the MNREGA. It may be concluded that there still exists inequality in all categories of land holdings and the reduction of 
inequality may be caused due to reason that the members of all categories of land holdings obtained more employment opportunities under MNREGA.

Note: On behalf of all authors, the corresponding author states that there is no conflict of interest.

\section{REFERENCES}

Balisacan, M and Are Semi. 1993. Agricultural Growth, Landlessness Rural, Off Farm Employment and Rural Poverty in Philippines. Economic Development and Cultural Changes, 39(3): 537.

Banerjee, Caustav and Saha, Partha. 2010. The NREGA, the Maoists and the Development Woes of the Indian State. Economic and Political Weekly, 45(28): 42-47.

Croxton, Frederic et al. 1979. Applied General Statistics, 19293 p. Prentice Hall of India Pvt. Ltd., New Delhi, India.

Department of Economics and Social Affairs. 1975. Poverty Unemployment and Development Policy: A case Study of Selected Issues with Reference to Kerala, 7 p. New York, United Nation.
Government of Himachal Pradesh. 2015. Annual Progress Report. 144 p. Department of Rural Development, Shimla, H.P., India.

Government of Himachal Pradesh, 2015. Economic Survey of Himachal Pradesh. 144 p. Economics and Statistics Department of Himachal Pradesh, Shimla, H.P., India.

Hirway, Indira. 2005. Enhancing Livelihood Security Through The Natinal Employment Guarantee Act: Towards Effective Operationalisation of the Act. The Indian Journal of Labour Economics, 48(4): 701 - 714.

Rajanna, Mamidipally and Ramesh, Gundeti. 2009. NREGP Facet of Inclusive Growth- A Study of Karimnagar District in Andhra Pradesh. Kurukshetra, 57(4): 15-18.

Roy, Sanjay. 2009. Impact on Villagers in Tripura- Field Study. Kurukshetra, 58(2): 27-28.

Sen, Amartya. 1974. Poverty, Inequality and Unemployment: Some Conceptual Issues of Measurement in Poverty and Income Distribution, Statistical Publishing Society, Calcutta, India.

Sontakki Bharat S. and Ahire, Laxman M. 2011. From the Ground Rural Employment Guarantee Scheme: Boon or bane to Indian Agriculture? Kurukshetra, 59(6): 40. 
